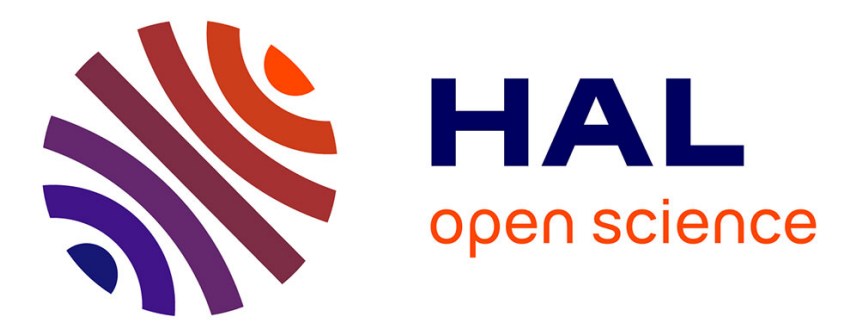

\title{
Experimental evaluation of the elastic limit of carbon-fibre reinforced epoxy composites under a large range of strain rate and temperature conditions
}

M. Castres, J. Berthe, E. Deletombe, M. Brieu

\section{- To cite this version:}

M. Castres, J. Berthe, E. Deletombe, M. Brieu. Experimental evaluation of the elastic limit of carbonfibre reinforced epoxy composites under a large range of strain rate and temperature conditions. Strain, 2017, 53 (6), pp.e12248. 10.1111/str.12248 . hal-01664778

\section{HAL Id: hal-01664778 \\ https://hal.science/hal-01664778}

Submitted on 4 Oct 2021

HAL is a multi-disciplinary open access archive for the deposit and dissemination of scientific research documents, whether they are published or not. The documents may come from teaching and research institutions in France or abroad, or from public or private research centers.
L'archive ouverte pluridisciplinaire HAL, est destinée au dépôt et à la diffusion de documents scientifiques de niveau recherche, publiés ou non, émanant des établissements d'enseignement et de recherche français ou étrangers, des laboratoires publics ou privés.

\section{(c)(1)}

Distributed under a Creative Commons Attribution| 4.0 International License 


\title{
Experimental evaluation of the elastic limit of carbon-fibre reinforced epoxy composites under a large range of strain rate and temperature conditions
}

\author{
M. Castres ${ }^{1,2,3}$ (D) | J. Berthe ${ }^{1}\left(\mathbb{D} \mid\right.$ E. Deletombe ${ }^{1} \mid$ M. Brieu ${ }^{2,3}$
}

${ }^{1}$ ONERA - The French Aerospace Lab, F-59014 Lille Cedex, France

${ }^{2}$ Univ Lille Nord de France, F-59000 Lille, France

${ }^{3}$ Centrale Lille, LML, F-59650 Villeneuve D'Ascq, France

\section{Correspondence}

Magali Castres, ONERA - The French Aerospace Lab, F-59014, Lille Cedex,

France.

Email: magali.castres@onera.fr

Funding information

European Union, the French Government (MENRT, MoD); DGA (French Armament Procurement Directorate), the Nord-Pas de Calais Region

\begin{abstract}
The mechanical behaviour of organic matrix composite materials such as T700GC/M21 carbon fibre reinforced polymer (CFRP) is generally considered by the industry as being orthotropic elastic for the sizing of aeronautical structures under normal isothermal "static" flight loads. During the aircraft lifetime, it may be exposed to severe loading conditions at various temperatures. However, the mechanical behaviour of CFRP is known to exhibit a linear behaviour or a non-linear behaviour according to the types of loads that are considered creep or extreme conditions. The observed non-linearity can be commonly attributed to several physical phenomena such as non-linear viscosity, plasticity, or damage. In the literature, different models can be found that are based on three components: a first elastic reversible behaviour, a second non-linear behaviour, and a failure criterion. An important issue is to understand and characterize the transition between the elastic reversible behaviour and the non-linear behaviour. To answer this question, the present paper describes an experimental methodology that permits to evaluate this transition thanks to raw experimental data, and its application to a range of constant but different strain rate and temperature tests performed on the T700GC/M21 CFRP material.
\end{abstract}

\section{KEYWORDS}

dynamic properties, mechanical properties, non-linear behaviour, polymer-matrix composite, temperature dependency

\section{1 | INTRODUCTION}

Nowadays, composite materials are increasingly used in the transportation industry including aeronautics. For example, the quantity of composite materials in the last aircraft of the Airbus family represents more than 50\% of its structural weight. Composites allow to reduce the weight, to avoid corrosion, and to build complex parts more easily. During the aircraft's life, these parts may be exposed to severe loadings at various temperatures. These loads cover a wide spectrum of strain rates, from low to high, and a wide range of temperatures, at cruise altitude from low around $-50^{\circ} \mathrm{C}$ to medium around $50^{\circ} \mathrm{C}$. The composite material behaviour is known to be rate dependent ${ }^{[1-3]}$ and temperature dependent. ${ }^{[4-6]}$ To answer the needs of the aircraft industry, it is important to understand accurately the composite behaviour and the influence of these two parameters on it. 
The material studied in this work is a carbon fibre reinforced polymer (CFRP), and a carbon epoxy composite named T700GC/M21. The mechanical behaviour of this material is known to be strain rate and temperature dependent, ${ }^{[5-8]}$ especially for shear behaviour. ${ }^{[2,7,9]}$ Some studies have been performed which concerned the influence of temperature on CFRP materials. ${ }^{[5,6,9-11]}$ Their authors have shown that the shear modulus and the maximum stress increase with the decreasing temperature, ${ }^{[9]}$ and that the shear modulus decreases with the increasing temperature. ${ }^{[6,10]}$ Other studies have been performed concerning the influence of strain rates on CFRP materials. ${ }^{[1-3,7,8,12,13]}$ These studies have shown that the shear modulus, the compressive modulus, the transverse tensile, and the maximum stress increase with the increasing strain rates. The mechanical response of the CFRP, especially in shear, can be decomposed in two components: a first linear behaviour following by a non-linear behaviour. ${ }^{[2,7,9,12]}$ Some studies have been performed on the prediction of the non-linear response of CFRP. ${ }^{[8,14]}$ In order to describe the mechanical response of CFRPs, some authors typically proposed models that include three main components: a first elastic reversible behaviour then a non-linear behaviour of the material, which can be phenomenologically associated to viscosity again, plasticity, ${ }^{[15-18]}$ or damage ${ }^{[19-23]}$ following by the final rupture of the material. The elastic reversible behaviour of the material can be strain rate and temperature dependent, see for instance the viscoelastic linear model proposed by Berthe et al. to model the linear response of the T700GC/M21 material. ${ }^{[24]}$ Concerning the failure behaviour of the material, different criteria for composite materials can be found ${ }^{[25-30]}$ which can also be strain rate dependent. ${ }^{[18,31,32]}$ To the authors' knowledge, the value of the non-linear parameters of such models (including the non-linearity threshold, when it exists in the model) is usually characterized thanks to inverse methods.

The aim of the present paper is first to reveal the existence of such a non-linear behaviour transition threshold for the T700GC/M21 material, which would not be the expression of the viscoelastic behaviour of the material, and second, to propose a characterisation method of this threshold by direct exploitation of raw test data. Once studied and assessed, the characterisation method will be applied on T700GC/M21 material to study the possible strain rate and temperature dependency of the non-linear threshold (elastic limit).

For this purpose, an experimental investigation on the very non-linear shear behaviour of T700GC/M $21\left[ \pm 45^{\circ}\right]$ laminates was done using a large spectrum of constant strain rate and temperature tests using an hydraulic jack and an environmental chamber. The use of a linear viscoelastic model such as the one proposed by Berthe et al., ${ }^{[24]}$ does not allow to obtain a non-linear behaviour such as the one observed in the tests as shown in Figure 1 for $8.10^{-5} \mathrm{~m} / \mathrm{s}$ strain rate. The works presented aim at proposing an experimental detection method to evaluate this non-linear threshold. From the raw test data, a specific method was first applied to determine the elastic shear modulus very accurately for each test and test specimen (and deal with variability), which then led to propose a simple method to detect the elastic limit thanks to a linear deviation measurement on stress/strain curves compared to the theoretical elastic shear linear response. Then, the influence of the strain rate and temperature on this threshold could be studied and compared with other results from the literature. Finally, the proposed method was applied to another material than T700GC/M21 to assess its robustness and generality.

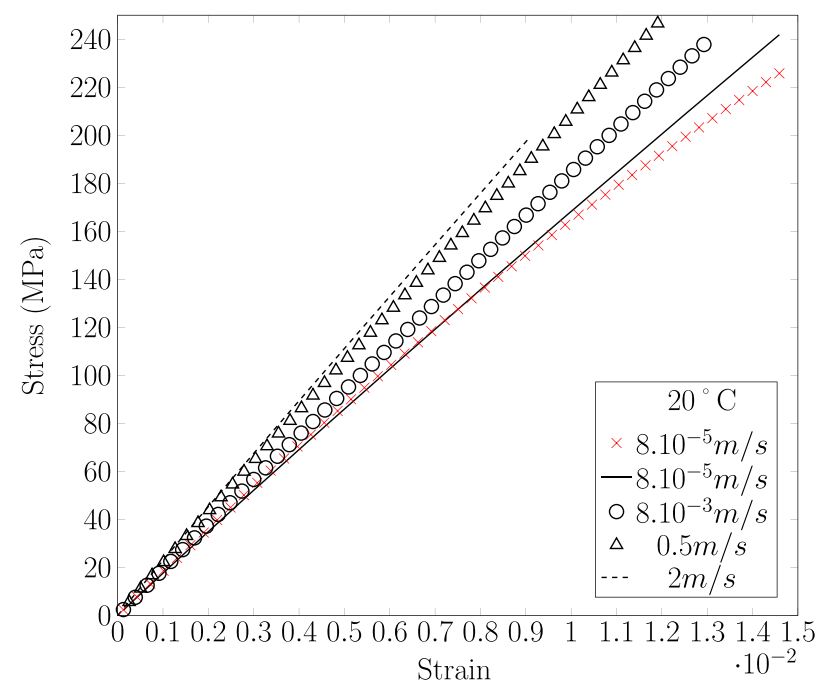

FIGURE 1 T700GC/M21 stress/strain curves of the linear viscoelastic model's response at $20^{\circ} \mathrm{C}$ and for different strain rates (black marker) compared with experimental data obtained at $8.10^{-5} \mathrm{~m} / \mathrm{s}(\mathrm{x})$ and $20^{\circ} \mathrm{C}$ 

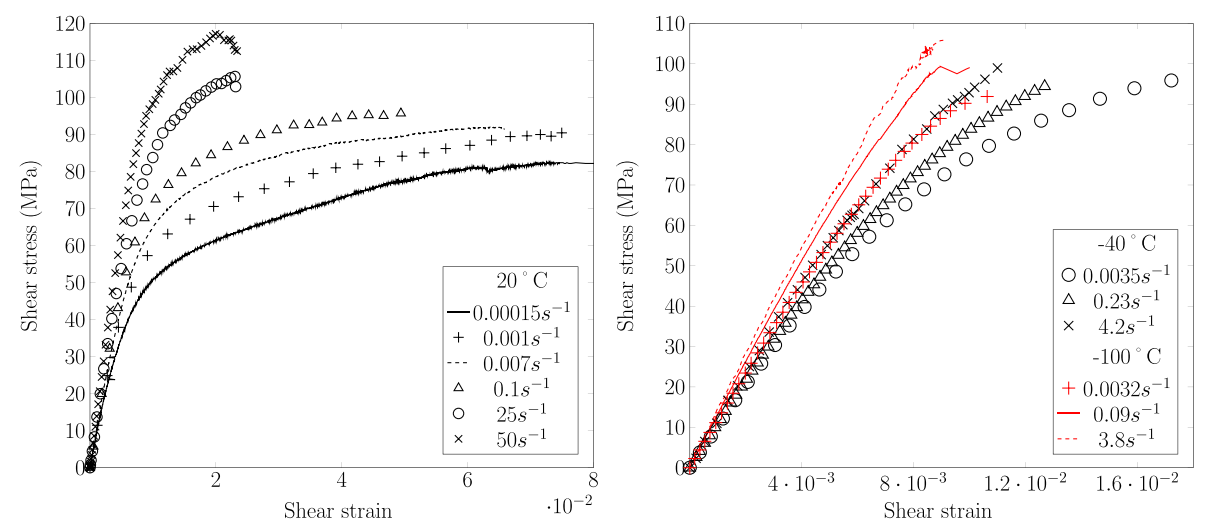

FIGURE 2 T700GC/M21 shear stress/strain at $20^{\circ} \mathrm{C}^{[24]}$ (left) and shear stress/strain at $-40^{\circ} \mathrm{C}$ and $-100^{\circ} \mathrm{C}$ (right) ${ }^{[33]}$

\section{2 | MATERIALS AND METHODS}

\section{1 | Material and tests}

As previously said, the studied material was a $\left[ \pm 45^{\circ}\right]$ composite laminate made of four plies of M21 epoxy resin and T700GC carbon fibres that had been cured with a typical cure cycle. The specimen shape was a rectangular one for the tests at ambient temperature, and a dog bone one for the tests at low temperature for practical reasons. Indeed, the load cell is a piezoelectric one, therefore, it has to be set outside the environmental chamber to avoid drift due to temperature and consequently provide a robust load measurement. The specimen inside the chamber is stiffer than outside the chamber. Consequently, a dogbone specimen has to be used in order to ensure that maximum stress and strain for the specimen develop inside the chamber. These dogbone sample geometries had been validated by Berthe et al. as they gave the same material mechanical parameters. ${ }^{[33]}$ Two strain gauges were glued on opposite faces of the specimen to measure the longitudinal and transverse strains. For ambient tests, strain gauges TML YFLA-2 were used, and for low temperature tests, strain gauges CFLA-3-350-11 were used. These strain gauges were conditioned using a VISHAY 2310 conditioner with a $75 \mathrm{kHz}$ cutting frequency and a quarter bridge configuration. All tests were performed with a Schenck servo hydraulic jack with a $\pm 200 \mathrm{kN}$ piezoelectric cell, except for tests at $0.5 \mathrm{~mm} / \mathrm{min}$ which were done with an INSTRON 5887 machine with a maximum capacity of $300 \mathrm{kN}$. Various upper holder speeds were tested, six speeds at ambient temperature, between $0.5 \mathrm{~mm} / \mathrm{min}$ and $2 \mathrm{~m} / \mathrm{s}$ and three speeds at $-40^{\circ} \mathrm{C}$ and $-100^{\circ} \mathrm{C}$, between $50 \mathrm{~mm} / \mathrm{min}$ and $0.5 \mathrm{~m} / \mathrm{s}$. For dynamic tests, a Kistler piezoelectric cell was used to measure the load. Signals were recorded using a $1 \mathrm{MHz}$ data acquisition system Nicolet Multipro. For tests at low temperature, an environmental chamber, in which the low temperature was controlled by liquid nitrogen, had been designed by Berthe. ${ }^{[33]}$ The obtained shear stress-strain curves are plotted in Figure 2 .

The shear behaviour clearly changes with the strain rate and the temperature. The material stiffness seems to be strain rate and temperature dependent. The results obtained for the shear modulus had already been studied by Berthe et al. ${ }^{[33]}$ and modelled to take the temperature and the strain rate dependencies into account.

Note that the stress-strain curves at $-40^{\circ} \mathrm{C}, 4.2 \mathrm{~s}^{-1}$ and at $-100^{\circ} \mathrm{C}, 0.0032 \mathrm{~s}^{-1}$, plotted on the right hand side in Figure 2, seem to superimpose. Furthermore, the evaluated shear modulus were similar: $5,881 \mathrm{MPa} \pm 5.8 \%$ for $-40^{\circ} \mathrm{C}$ and $4.2 \mathrm{~s}^{-1}$ test and $5,860 \mathrm{MPa} \pm 3 \%$ for $-100^{\circ} \mathrm{C}$ and $0.0032 \mathrm{~s}^{-1}$ test.

The shear behaviour can clearly be split into two different domains, a linear and a non-linear one. The transition between these two domains is hereafter referred to as being the elastic limit of the material. Indeed, the observed non-linear behaviour cannot be attributed to a viscoelastic effect. The plotted curves in Figure 2 seem to reveal a change of the non-linear behaviour, which has not yet been studied. For this reason, the present paper proposes a method based on a linearity deviation detection to accurately identify this transition between the linear and the non-linear domains and the evolution of this transition with the temperature and the strain rate. The proposed method is introduced in more details in the following paragraph.

\section{2 | Evaluation of the elastic limit}

To identify the elastic limit, a linear elastic response (no viscoelastic effects) is taken as a reference, assuming that the elastic Hooke's law applies for the T700GC/M21 material. It is then proposed to measure the linearity deviation of the 
stress/strain test curves compared to the Hooke's law. For this purpose, theoretical stress $\left(\sigma_{\text {theor }}\right)$ and strain $\left(\varepsilon_{\text {theor }}\right)$ are straight reconstructed as follows:

$$
\begin{gathered}
\sigma_{\text {theor shear }}=2 * G_{12}(\dot{\varepsilon}, T) * \varepsilon_{\text {expe shear }}, \\
\varepsilon_{\text {theor shear }}=\frac{\sigma_{\text {expe shear }}}{2 * G_{12}(\dot{\varepsilon}, T)},
\end{gathered}
$$

where $G_{12}$ is the shear modulus defined by Hooke's law. This modulus must then be accurately evaluated for each test, for the different constant temperatures and strain rates. In the present case, it is performed thanks to a regression method applied on the strain interval that gives the optimal correlation factor. In the standard, ${ }^{[34-36}$ the shear modulus is evaluated for quasi-static loadings using a chord method over a strain range interval, for example, $\operatorname{in}^{[34]} \varepsilon=\left[5.10^{-4}-2,5.10^{-3}\right]$. This standard does not seem to be appropriate in the case presented here because the linear range is obviously different according to the strain rate (see Figure 2). Therefore, to evaluate the shear modulus in this study a different method is proposed. This method is based on successive linear regressions. Indeed, a first linear regression is performed considering the first experimental points over the measurement uncertainties, and then another experimental point is added and another linear regression is performed until every experimental points are taken into account. For each linear regression, a correlation coefficient is evaluated. The shear modulus value corresponds to the slope of the linear regression with the higher correlation coefficient therefore corresponding to the linear regime and interval. For each test, the constant strain rate assumption on the strain interval used for the evaluation of the shear modulus is verified. Then, the theoretical elastic stress/strain curves are compared to their experimental counterparts $\left(\varepsilon_{\text {expe shear }}\right.$ and $\left.\sigma_{\text {expe shear }}\right)$. To quantify the linearity deviation, the distance between these two stresses, or strains, is calculated such as described in Equations 3 and 4:

$$
\begin{aligned}
& d_{1}=\frac{\left|\sigma_{\text {expe shear }}-\sigma_{\text {theor shear }}\right|}{\sigma_{\text {expe shear }}}, \\
& d_{2}=\frac{\left|\varepsilon_{\text {expe shear }}-\varepsilon_{\text {theor shear }}\right|}{\varepsilon_{\text {expe shear }}}
\end{aligned}
$$

Figure 3 illustrates the results obtained with the proposed method: the calculation of the linearity deviation according to the measured stress is plotted in this case. At the beginning of the tests, because of the small strain levels and measurement noise, the stress linear deviation also suffers from important noise which progressively decreases when the strain increases. Figure 3 clearly reveals two domains, a first one where the noisy deviation level decreases, followed by a second one where the deviation monotonically increases. One could assume that the deviation stops to be random, and that it becomes driven by a physical phenomenon in the second domain. Let's then postulate that the linear transition would be at the inflexion point. Unfortunately, this point is difficult to catch accurately. As it will be described in this paper, the first step was to choose a given deviation value after the inflexion point ( $5 \%$ in the following paragraphs) to deal with this difficulty. This value gives to the non-linear stress or strain threshold or elastic limit, a well identified and conservative value, $\sigma_{d_{5 \%}}$ or $\varepsilon_{d_{5 \%}}$.
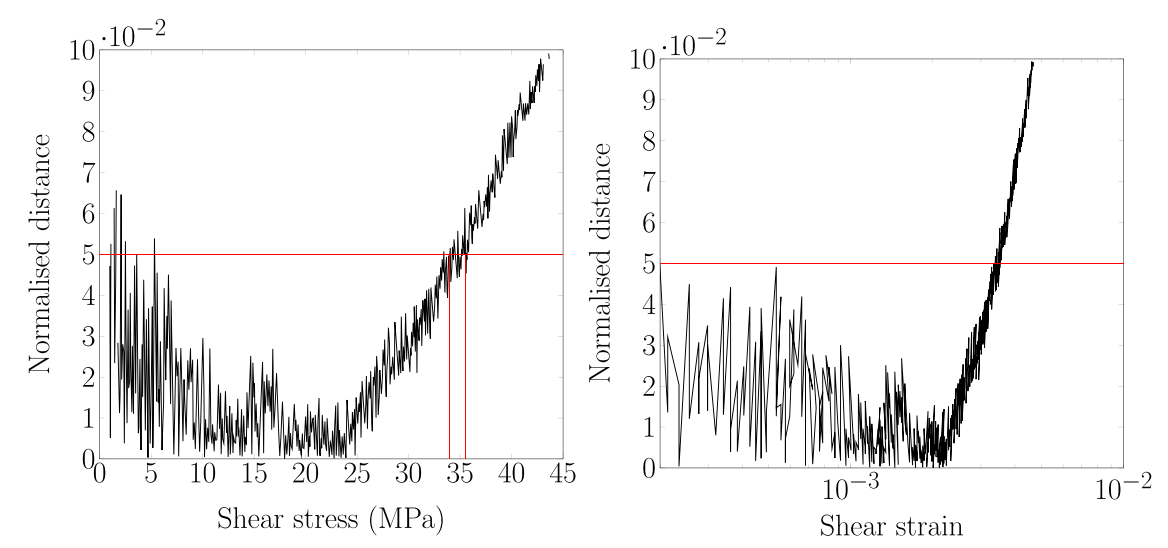

FIGURE 3 Evolution of normalized distance $d_{1}$ with the shear stress (left) and $d_{2}$ with the shear strain (right) at $20^{\circ} \mathrm{C}$ and $0.1 s^{-1}$ 
In the subsequent sensitivity analysis, the material will be considered to be linear as long as $d<5 \%$, in the second domain. It is noticeable that an uncertainty about the limit value can be observed if you consider the first or last points for which $\mathrm{d}>5 \%$ or $\mathrm{d}<5 \%$ (two red lines on the right hand side of Figure 3). This uncertainty is related to the measurement noise. Then, error bars can be given for the $\sigma_{d_{5 \%}}$ and $\varepsilon_{d_{5 \%}}$ values in the following analysis.

\section{3 | RESULTS}

Thanks to the previously described method, the $\sigma_{d_{5 \%}}$ shear stress limit and $\varepsilon_{d_{5 \%}}$ shear strain limit versus strain rate can be plotted (with error bars). The next paragraph aims at analysing these figures. Note that it would also be possible to plot the non-linear stress or strain with respect to any value of the deviation (lower or higher than 5\%), for the different strain rate and temperature tests.

\section{1 $\mid \sigma_{d_{5 \%}}$ and $\varepsilon_{d_{5 \%}}$ :application to T700GC/M21}

The purpose of this section is to study the evolution of the $\sigma_{d_{5 \%}}$ stress and $\varepsilon_{d_{5 \%}}$ strain limits for the T700GC/M21 composite material for different strain rate and different temperature tests. At least three tests were performed, except for the $10^{-4} s^{-1}$ strain rate where only two tests were done for each strain rate at each temperature. The previously described method is applied to each test. The normalised distances for the three tests were plotted on the same figure, as shown in Figure 4. This kind of graph allows to add deviations to uncertainties for the $d_{5 \%}$ stress or strain limit to take the experimental noise and experimental dispersion together into account in error bars. These values are summarised in Table 1 . The $d_{5 \%}$

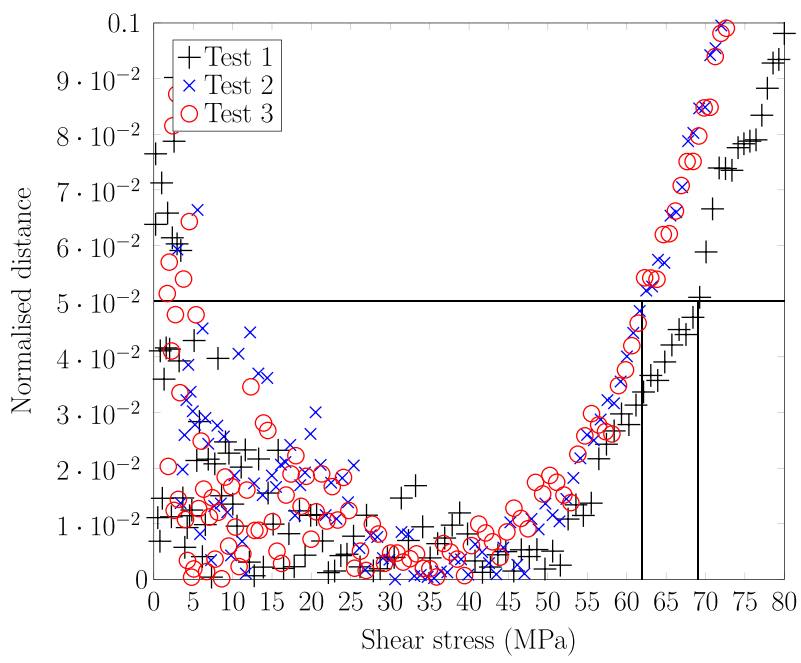

FIGURE 4 Determination of $\sigma_{d_{5 \%}}$ stress limit for test at $20^{\circ} \mathrm{C}$ and $2 \mathrm{~m} / \mathrm{s}$ for T700GC/M21

TABLE 1 T700GC/M21 $d_{5 \%}$ shear stress-strain limit

\begin{tabular}{llll}
$\mathbf{T}\left({ }^{\circ} \mathbf{C}\right)$ & $\dot{\varepsilon}\left(s^{-1}\right)$ & $\varepsilon_{d_{5 \%}}\left(10^{-3}\right)$ & $\sigma_{d_{5 \%}}(M P a)$ \\
\hline 20 & $1.10^{-4}$ & $2.5 \pm 6 \%$ & $19.75 \pm 4 \%$ \\
& $1.10^{-3}$ & $2.7 \pm 7 \%$ & $25 \pm 7 \%$ \\
& $7.10^{-3}$ & $3.3 \pm 6 \%$ & $30 \pm 6 \%$ \\
& 0.1 & $3.6 \pm 8 \%$ & $35 \pm 8 \%$ \\
& 25 & $3.4 \pm 9 \%$ & $37.5 \pm 9 \%$ \\
-40 & 50 & $5.25 \pm 5 \%$ & $65.5 \pm 4 \%$ \\
& $3.5 .10^{-3}$ & $3.85 \pm 4 \%$ & $37.25 \pm 3 \%$ \\
& 0.23 & $4.45 \pm 3 \%$ & $46 \pm 2 \%$ \\
-100 & 4.2 & $5.0 \pm 4 \%$ & $56 \pm 12 \%$ \\
& $3.2 .10^{-3}$ & $4.65 \pm 5 \%$ & $50.5 \pm 3 \%$ \\
& 0.09 & $5.65 \pm 3 \%$ & $68.5 \pm 2 \%$ \\
& 3.8 & $6.75 \pm 1 \%$ & $79 \pm 10 \%$
\end{tabular}


stress and strain limits clearly proved to be strain rate and temperature dependent. When the temperature decreased, the $d_{5 \%}$ limit increased, and when the strain rate increased, the $d_{5 \%}$ limit increased too. When the strain rate increased from $1.10^{-4}$ to $50 \mathrm{~s}^{-1}$ at $20^{\circ} \mathrm{C}$, the $d_{5 \%}$ stress limit increased by $232 \%$, and the $d_{5 \%}$ strain limit increased by $110 \%$. When the temperature decreased from $20^{\circ} \mathrm{C}$ to $-100^{\circ} \mathrm{C}$ at $0.1 \mathrm{~s}^{-1}$, the $d_{5 \%}$ stress limit increased by $96 \%$, and the $d_{5 \%}$ strain limit increased by $57 \%$. One should note that the same sensitivity trends to the strain rate and temperature were already noticed by Berthe et al. ${ }^{[24,33]}$ when studying the T700GC/M21 viscoelastic shear modulus . Moreover, the $d_{5 \%}$ stress and strain limits obtained for tests at $-40^{\circ} \mathrm{C}, 0.5 \mathrm{~m} / \mathrm{s}$ and $-100^{\circ} \mathrm{C}, 50 \mathrm{~mm} / \mathrm{min}$ were again very similar. On the right hand side in Figure 5, one can note that the $d_{5 \%}$ strain limit at $25 \mathrm{~s}^{-1}$ was lower than the $d_{5 \%}$ limit at $0.1 \mathrm{~s}^{-1}$. This result can be due to perturbations owed to experimental tests like rate variations, problem in temporal reconstruction, or maybe to a physical reason like the measurement difficulty in a transition area (see Section 4, Discussion and conclusion).

In Figure 5, the $d_{5 \%}$ stress (left) and strain (right) limits with respect to the strain rate are plotted for three different temperatures.

To interpret these results and particularly the $d_{5 \%}$ stress limit, an acoustic emission analysis was performed on two specimens of T700GC/M21 [ \pm 45$]$ at $1.10^{-3} \mathrm{~S}^{-1}$ and at $20^{\circ} \mathrm{C}$. The shape of the specimens was the same as the one used in Section 2.1. These tests led to a first set of acoustic activities being detected between $18 \mathrm{MPa}$ and $28.5 \mathrm{MPa}$. The acquisition threshold was set to $40 \mathrm{~dB}$. In the literature, different studies can be found about the acoustic emission analysis performed on CFRP. ${ }^{[37,38]}$ These works have shown that each damage has different acoustic signature, and these authors proposed to class these phenomena (matrix cracking, debonding of fibre matrix, interface failure, and fibre breakage) thanks to their frequencies or their amplitudes. According to the acquisition threshold, the first acoustic signal could be due to either matrix cracking or debonding of fibre matrix. Interestingly, quasi-static tests performed by Huchette on T700GC/M21 [39]
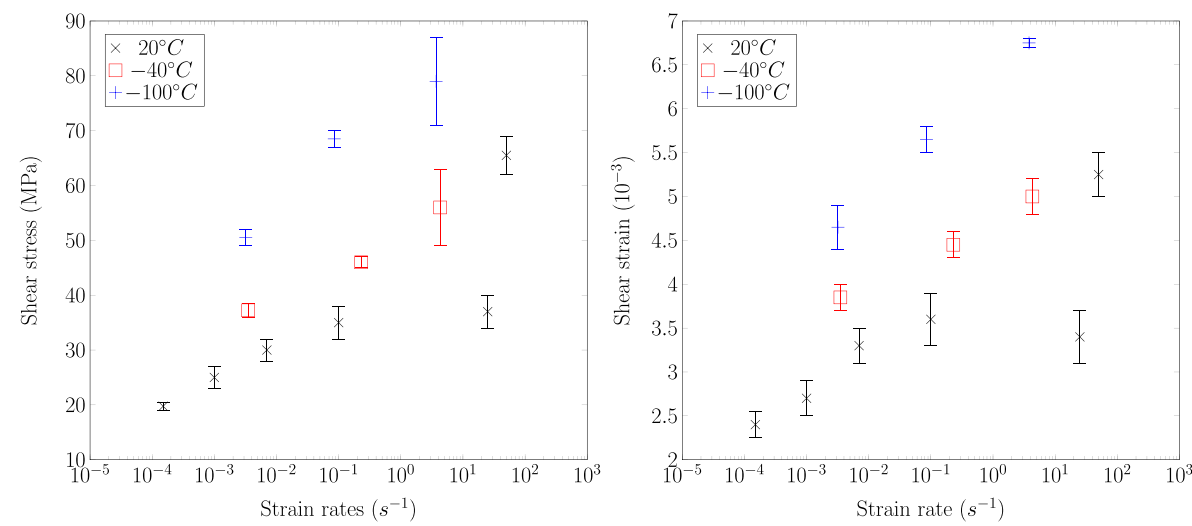

FIGURE 5 Study of the strain rate sensitivity of $\sigma_{d_{5 \%}}$ shear stress and $\varepsilon_{d_{5 \%}}$ shear strain limit at various temperatures for T700GC/M21

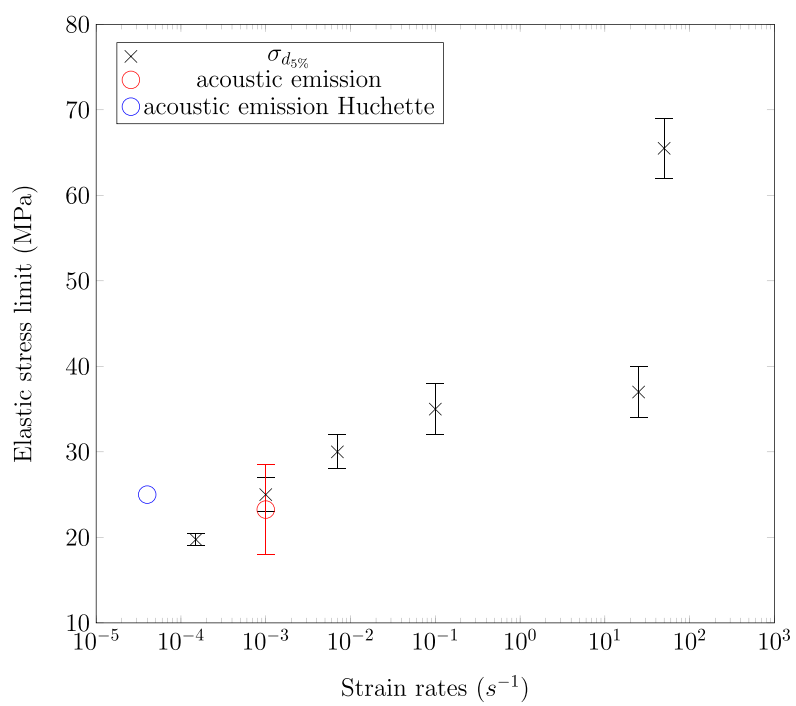

FIGURE 6 Comparison between the experimental $d_{5 \%}$ shear stress limit and initiation acoustic activities at $20^{\circ} \mathrm{C}$ for T700GC/M21 
also acoustically detected a damage initiation around $25 \mathrm{MPa}$ for a $4.10^{-5} \mathrm{~s}^{-1}$ strain rate test. These points are plotted in Figure 6 (red circles and blue crosses). The correlation between these observations and the $d_{5 \%}$ shear stress limit obtained with the previously described method could support the idea that the loss of linearity might be related to the appearance of damage in the composite material (and not to plasticity developing in the resin). Then, it could also mean that damage initiation might be detected without acoustic means thanks to the proposed method, whatever the test speed and temperature.

It can obviously be argued that the gross criterion does not accurately detect the transition value between the linear and non-linear behaviours. A possible way to evaluate the correspondence of the $d_{5 \%}$ shear stress or strain limits with the true material elastic limits could be to check the duality of these $d_{5 \%}$ stress and strain values. Indeed, the elastic shear stress and strain limits of any material are dual parameters of elasticity by definition and so should it be for their limits. The question now is to define how to check if the $d_{5 \%}$ stress and strain limit are dual, which means if there is a simple equivalence rule between them (the Hooke's law).

\section{2 | Duality of stress or strain $d_{5 \%}$ limits}

So for each strain rate and temperature test, the $d_{5 \%}$ stress and strain limit are first calculated. Then, the Hooke's law is applied to estimate a theoretical elastic stress limit $\sigma_{e}^{*}$ thanks to the shear modulus, and the $\varepsilon_{d_{5 \%}}$ strain limit obtained experimentally:

$$
\sigma_{e}^{*}=2 * G_{12}(\dot{\varepsilon}, T) * \varepsilon_{d_{5 \%}} .
$$

Then, this $\sigma_{e}^{*}$ is compared to $\sigma_{d_{5 \%}}$ obtained with the linearity deviation method. $\sigma_{e}^{*}$ and $\sigma_{d_{5 \%}}$ were plotted in Figure 7. $\sigma_{e}^{*}$ quite well corresponded to $\sigma_{d_{5 \%} \%}$. The proposed $\sigma_{d_{5 \%}}$ and $\varepsilon_{d_{5 \%}}$ parameters then seemed to be dual in the Hooke sense for tests at $20^{\circ} \mathrm{C}$. The same analysis was also conducted on tests at $-40^{\circ} \mathrm{C}$ and $-100^{\circ} \mathrm{C}$, and the same conclusion was obtained. Moreover, the proposed method proved to be robust because on Figure 7, one may notice that results were not affected by the dynamic perturbations of the force signal. One can possibly guess that the correspondence would be even better if $d_{1 \%}$ limit values were used to calculate the elastic limit.

Finally to strengthen the previous conclusions and increase confidence in the proposed criterion, the method was applied to another material, the G939/M18 CFRP woven composite which was tested in the lab several years ago. Results are presented in the following section.

\section{3 | Application of non-linear deviation method to G939/M18 composite material}

The linearity deviation method was applied to the CFRP G939/M18 woven material. This material was tested in [ $\left.\pm 45^{\circ}\right]$ dynamic tension tests at three different temperatures: ambient, $-20^{\circ} \mathrm{C}$, and $-55^{\circ} \mathrm{C}$, and for three different strain rates: $0.001,0.1$, and $200 \mathrm{~s}^{-1}$.

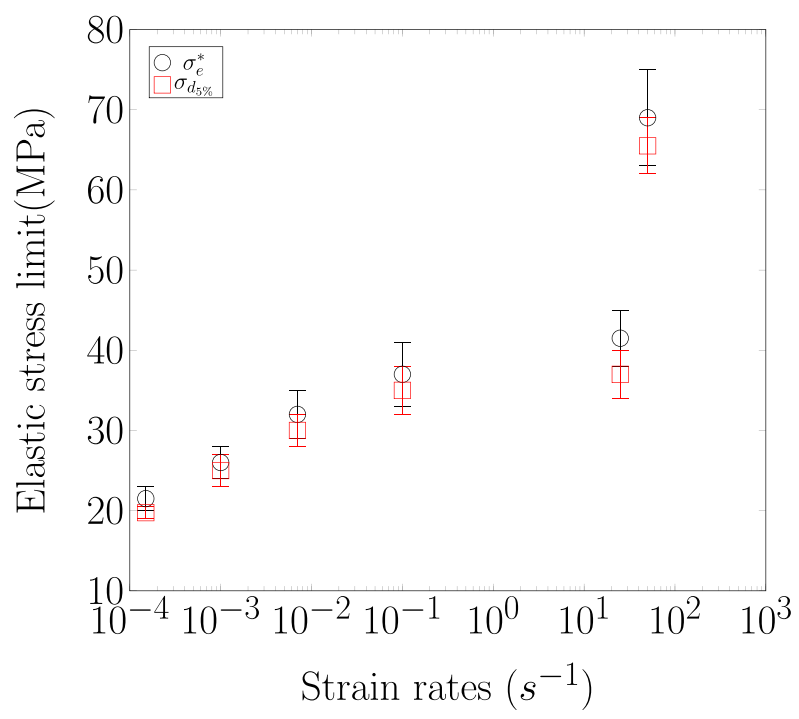

FIGURE 7 Comparison of $\sigma_{e}^{*}$ and $\sigma_{d_{5 \%}}$ for T700GC/M21 at $20^{\circ} \mathrm{C}$ 
TABLE $2 d_{5 \%}$ shear stress-strain limit for G939/M18

\begin{tabular}{llll}
$\mathbf{T}\left({ }^{\circ} \boldsymbol{C}\right)$ & $\dot{\varepsilon}\left(s^{-1}\right)$ & $\varepsilon_{d_{5 \%}}\left(10^{-3}\right)$ & $\sigma_{d_{5 \%}}(M P a)$ \\
\hline 20 & $1.75 .10^{-3}$ & $3.5 \pm 6 \%$ & $28.5 \pm 13 \%$ \\
& 0.1 & $4.75 \pm 12 \%$ & $34.5 \pm 10 \%$ \\
& 336 & $11.5 \pm 4 \%$ & $95 \pm 1 \%$ \\
-20 & $1.10^{-3}$ & $5.3 \pm 14 \%$ & $37.5 \pm 9 \%$ \\
& 0.09 & $4.95 \pm 2 \%$ & $39.5 \pm 3 \%$ \\
& 108 & $12.25 \pm 2 \%$ & $117.5 \pm 2 \%$ \\
-55 & $1.10^{-3}$ & $5.25 \pm 18 \%$ & $45 \pm 15 \%$ \\
& 0.08 & $6.5 \pm 8 \%$ & $55 \pm 9 \%$ \\
& 139 & $13 \pm 9 \%$ & $142 \pm 3 \%$ \\
\hline
\end{tabular}
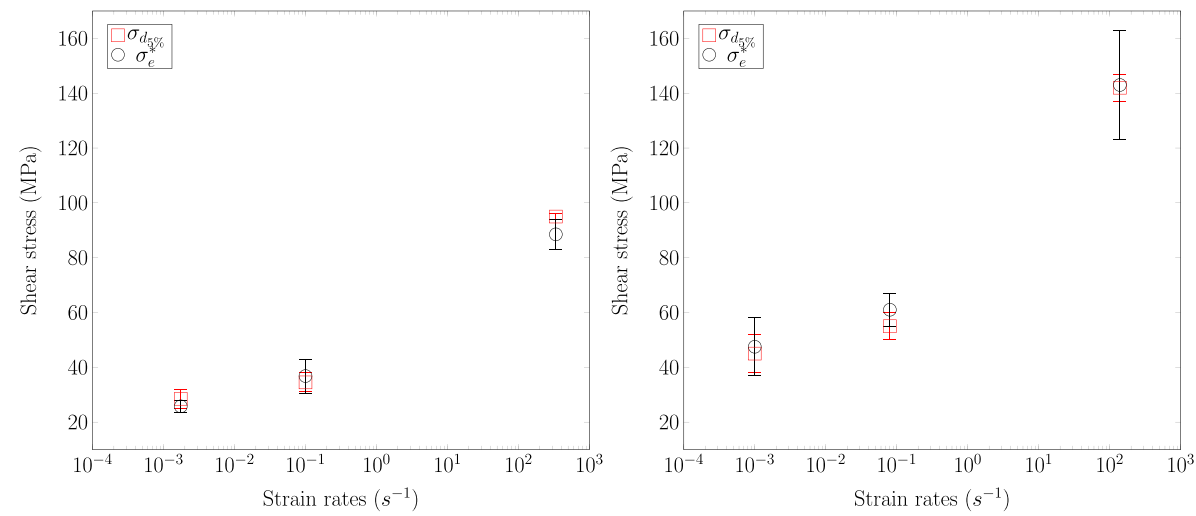

FIGURE 8 Comparison of $\sigma_{e}^{*}$ and $\sigma_{d_{5 \%}}$ at $20^{\circ} \mathrm{C}$ (left) and at $-55^{\circ} \mathrm{C}$ (right) for G939/M18

In the same way, as previously $d_{5 \%}$ stress-strain limits were calculated. The obtained values are summarised in Table 2. The same trend as for T700GC/M21 was observed in terms of influence of strain rate and of temperature on the $d_{5 \%}$ limit. When the strain rate increased from $3.10^{-3}$ to $236 \mathrm{~s}^{-1}$ at $20^{\circ} \mathrm{C}$, the $d_{5 \%}$ stress limit increased by $230 \%$, and the $d_{5 \%}$ strain limit increased by $228 \%$. When the temperature decreased from $20^{\circ} \mathrm{C}$ to $-55^{\circ} \mathrm{C}$ at $0.1 s^{-1}$, the $d_{5 \%}$ stress limit increased by $59 \%$, and the $d_{5 \%}$ strain limit increased by $36 \%$.

As previously, the duality of the criteria was studied. Results are presented in Figure 8. The proposed $\sigma_{d_{5 \%}}$ and $\varepsilon_{d_{5 \%}}$ seem to be dual for tests at $20^{\circ} \mathrm{C}$ for G939/M18 material. The same conclusion can be made at $-20^{\circ} \mathrm{C}$ and $-55^{\circ} \mathrm{C}$.

\section{4 | DISCUSSION AND CONCLUSION}

The soundness of the results obtained thanks to the previous method has first to be evaluated. For that, the claimed results and trends were compared with others from the literature concerning yield stresses of polymers, which is a well documented topic. In fact, for polymers, there is a list of methods that can be used to characterise the elastic limit criterion. ${ }^{[11,40-44]}$ Some other studies deal with the influence of temperature and strain rate on polymers yield stress. ${ }^{[40-42]}$ They concluded that their yield stress increased with decreasing temperature and with increasing strain rate. Effects of temperature and strain rate on apparent modulus and yield stress of resin epoxy RTM6 were also studied. ${ }^{[44]}$ The conclusions were the same as for the above mentioned polymer materials and T700GC/M21 composite material. Other studies pointed out that there is a time-temperature equivalence for polymer materials. ${ }^{[45,46]}$ This principle can be described by different formulations, like Arrhénius or Williams-Landel-Ferry laws. Classically, these laws are analysed as a translation of studied values, on the left-hand side, for a decrease of temperature. The same trend was observed for the $\sigma_{d_{5 \%}}$ and $\varepsilon_{d_{5 \%}}$. Moreover, one may notice that there is an observable transition slope around $10 \mathrm{~s}^{-1}$. A similar trend was already observed on the evolution of shear modulus of the T700GC/M21 with respect to the strain rate in Berthe et al. ${ }^{[24,33]}$ Some studies about the evolution of the epoxy resins yield stress ${ }^{[11,44]}$ highlighted the same tendency with a slope transition. If the polymer literature is considered, some models used to describe the evolution of yield stress or strain are based on the introduction of the contribution of different mechanical transition contributions (like $\alpha$ mechanism or $\beta$ mechanism 
contributions). ${ }^{[40,41,42,43,47]}$ If the same parallel is done for the $\sigma_{d_{5 \%}}$ evolution, the transition slope could be explained by a mechanical transition contribution, like $\beta$ transition. ${ }^{[24,33]}$

In the present work, a method to define the elastic stress and strain limits of CFRP materials was studied (in fact, a $d_{5 \%}$ approximation of this elastic limit is used in the present paper for practical reasons). These criteria are based on the detection of loss of linearity and only rely on the direct use of raw experimental data. The method is simply based on the linearity deviation compared to the theoretical Hooke's elastic stress/strain response of the composite material. The main advantage of this method is its accuracy (thanks to the determination of the accurate elastic shear modulus for each single test) and its robustness (thanks to its low sensitivity to noise). It was used to obtain the elastic limit of the T700/M21 composite material for different temperatures and strain rates tests. The influence of the temperature and strain rate is as follows: the elastic limit increases with the increasing strain rate and the decreasing temperature. The meaning of this elastic limit was investigated thanks to an acoustic emission analysis that revealed noticeable acoustic activities (for the $20^{\circ} \mathrm{C}$ and $5 \mathrm{~mm} / \mathrm{min}$ tests) at approximately the same load level as the established elastic limit. These conclusions were confirmed on two different CFRP epoxy composite materials of aeronautical quality (T700GC/M21 and G939/M18), which strengthens the paper conclusions. The next step of the work will deal with the formulation of a strain rate and temperature dependent model of this elastic limit evolution. Now that the non-linear transition can be accurately characterised, the physical analysis of the driving phenomena behind the initiation of non-linearity will then be more thoroughly studied. For this purpose, the experimental investigation of this material could be completed by some load/unload tests at different strain rates to observe the evolution of residual strains and shear modulus at each cycle for different strain rates.

\section{ACKNOWLEDGEMENTS}

The authors would like to thank the European Union, the French Government (MENRT, MoD), the DGA (French Armament Procurement Directorate), and the Nord-Pas de Calais Region (especially within the context of the CISIT project) for funding research studies and equipment that contributed to this research work.

\section{ORCID}

M. Castres (1) http://orcid.org/0000-0002-8534-2741

J. Berthe $(1)$ http://orcid.org/0000-0003-1383-5923

\section{REFERENCES}

[1] G. C. Jacob, J. M. Starbuck, J. F. Fellers, S. Simunovic, R. G. Boeman. J. Appl. Polym. Sci. 2004, 94(1), 296.

[2] I. M. Daniel, J.-M. Cho, B. T. Werner, J. S. Fenner. AIAA J. 2011, 49(8), 1658.

[3] R. O. Ochola, K. Marcus, G. N. Nurick, T. Franz. Compos. Struct. 2004, 63(3-4), 455.

[4] T. G. del Río, E. Barbero, R. Zaera, C. Navarro. Compos. Sci. Technol. 2005, 65(1), 61.

[5] K. Morioka, Y. Tomita, K. Takigawa. Mater. Sci. Eng. A 2001, 319-321, 675.

[6] S. Cao, Z. Wu, X. Wang. J. Compos. Mater. 2009, 43(4), 315-330.

[7] A. Gilat, R. K. Goldberg, G. D. Roberts. Compos. Sci. Technol. 2002, 62(10-11), 1469.

[8] C. A. Weeks, C. T. Sun. Compos. Sci. Technol. 1998, 58(3), 603.

[9] A. T. Nettles, E. J. Biss, Low Temperature Mechanical Testing of Carbon-fiber/Epoxy-resin Composite Materials, NASA/Marshall Space Flight Center Center/MSFC,Alabama 1996.

[10] J. Melo, D. Radford. J. Compos. Mater. 2004, 38(20), 1815-1830.

[11] J. L. Jordan, J. R. Foley, C. R. Siviour. Mech. Time-Depend. Mater. 2008, 12(3), 249.

[12] H. M. Hsiao, I. M. Daniel. Compos. Part B: Eng. 1998, 29(5), 521.

[13] S. E. Groves, R. J. Sanchez, R. E. Lyon, A. E. Brown, in Eleventh Volume: Composite Materials-testing and Design, ASTM International 1993.

[14] T. A. Bogetti, C. P. Hoppel, V. M. Harik, J. F. Newill, B. P. Burns. Compos. Sci. Technol. 2004, 64(3-4), 329-342. Failure Criteria in Fibre Reinforced Polymer Composites Part C: Additional Theories Conclusions and Recommendations.

[15] P. Ladeveze, E. LeDantec. Compos. Sci. Technol. 1992, 43(3), 257.

[16] E. Abisset. 2012, A Damage Mesomodel of Laminated Composites for the Virtual Testing: Identification and Validation, phD Theses, École normale supérieure de Cachan - ENS Cachan.

[17] G. M. Vyas, S. T. Pinho, P. Robinson. Compos. Sci. Technol. 2011, 71(8), 1068. 
[18] L. Raimondo, L. Iannucci, P. Robinson, P. T. Curtis. Compos. Sci. Technol. 2012, $72(7), 819$.

[19] J. F. Maire, J. L. Chaboche. Aerosp. Sci. Technol. 1997, 1(4), 247.

[20] F. Laurin, N. Carrère, J.-F. Maire. Compos. Part A: Appl. Sci. Manuf. 2007, 38(1), 198.

[21] F. Laurin, N. Carrere, C. Huchette, J. F. Maire. J. Compos. Mater 2013, 47(20-21), 2713.

[22] V. Murari, C. S. Upadhyay. Compos. Struct. 2013, 96, 419.

[23] P. Maimí, P. P. Camanho, J. A. Mayugo, C. G. Dávila. Mech. Mater 2007, 39(10), 897.

[24] J. Berthe, M. Brieu, E. Deletombe. J. Compos. Mater. 2013, 47(14), 1717.

[25] Z. Hashin. J. Appl. Mech. 1980, 47(2), 329.

[26] A. Rotem. Compos. Sci. Technol. 1998, 58(7), 1083.

[27] A. Puck, H. Schürmann. Compos. Sci. Technol. 1998, 58(7), 1045.

[28] C. T. Sun, J. Tao. Compos. Sci. Technol. 1998, 58(7), 1125.

[29] S. T. Pinho, C. G. Dàvila, P. P. Camanho, L. Iannucci, P. Robinson. NASA/TM-2005-213530 2005.

[30] C. G. Dávila, P. P. Camanho. NASA TM 2003, 212663(613).

[31] I. M. Daniel, B. T. Werner, J. S. Fenner. Compos. Sci. Technol. 2011, 71(3), 357.

[32] Y. Tao, H. Chen, K. Yao, H. Lei, Y. Pei, D. Fang. Int. J. Solids Struct. 2017, 37-46.

[33] J. Berthe, M. Brieu, E. Deletombe, G. Portemont. Mater. Des. 2014, 62, 241.

[34] AITM 1-0002: Fibre Reinforced Plastic. Determination of in Plane Shear Properties $\left( \pm 45^{\circ}\right.$ tensile test $)$. Airbus Industrie Test Method: 1998 (AITM).

[35] NF EN ISO 14129: Composites Plastiques Renforcées de Fibres - Détermination de la Réponse Contrainte-Déformation en Cisaillement Plan, Module et Résistance Compris, par Essai de Traction à $\left( \pm 45^{\circ}\right)$ : 1998, AFNOR.

[36] ASTM D3518/D3518M-13, Standard Test Method for In-plane Shear Response of Polymer Matrix Composite Materials by Tensile Test of a $\left( \pm 45^{\circ}\right)$ Laminate, ASTM International, West Conshohocken, PA, 2013, www.astm.org.

[37] P. Nimdum, J. Renard, Use of Acoustic Emission to Discriminate Damage Modes in Composite-antenna-structure during Buckling Loading, in 15th International Conference on Experimental Mechanics 2012, 15-p.

[38] V. Munoz, B. Valès, M. Perrin, M. L. Pastor, H. Welemane, A. Cantarel, M. Karama. Compos. Part B: Eng. 2016, 85, 68.

[39] C. Huchette. 2005, Sur La Complémentarité des Approches Expérimentales et Numériques Pour La Modélisation des Mécanismes D'endommagement des Composites Stratifiés, Ph.D. Thesis, Université Paris VI.

[40] J. Richeton, S. Ahzi, L. Daridon, Y. Rémond. Polymer 2005, 46(16), 6035.

[41] J. Richeton, S. Ahzi, K. S. Vecchio, F. C. Jiang, R. R. Adharapurapu. Int. J. Solids Struct. 2006, 43(7-8), 2318.

[42] J. Richeton, S. Ahzi, L. Daridon, Y. Rémond. J. Phys. IV France 2003, 110, 39.

[43] R. M. Boumbimba, K. Wang, N. Bahlouli, S. Ahzi, Y. Rémond, F. Addiego. Mech. Mater. 2012, $52,58$.

[44] R. Gerlach, C. R Siviour, N. Petrinic, J. Wiegand. Polymer 2008, 49, 2728.

[45] M. L. Williams, R. F. Landel, J. D. Ferry. J. Am. Chem. Soc. 1955, 77(14), 3701.

[46] Y. T. Yeow, D. H. Morris, H. F. Brinson, Time-temperature Behavior of a Unidirectional Graphite/Epoxy Composite, in Composite Materials: Testing and Design (Fifth Conference), New Orleans, US, 1978. Rap. Tech. VPI-E-78-4, NASA.

[47] AD Mulliken, MC Boyce, Low to High Strain Rate Deformation of Amorphous Polymers, in Proceedings of the 2004 SEM X International Congress and Exposition on Experimental and Applied Mechanics, Costa Mesa, CA, US, 2004, 7. 